\title{
O poema vem como um cavalo: crítica, edição e criação pelas lentes de Júlia de Carvalho Hansen
}

\author{
Otávio Augusto de Oliveira Moraes*
}

\section{Apresentação}

Júlia de Carvalho Hansen nasceu em São Paulo, é formada em Letras pela Universidade de São Paulo e fez mestrado em Estudos Portugueses pela Universidade Nova de Lisboa. Ela é uma das editoras da Chão da Feira, além de astróloga e poeta.

A presente entrevista tem como origem a oficina "Grafar o vegetal", momento de leitura e criação poética sob a batuta da entrevistada e que teve como local o Sesc Palladium, em Belo Horizonte. A oficina teve três dias de duração e ocorreu em novembro de 2017. A entrevistada elaborou uma rota tríplice na constituição da oficina, mesclando leitura, crítica e criação poética. Dessa instigante atividade, da qual tive a oportunidade de participar, nasceu a vontade de construir esta conversa.

Em entrevista à página Escamandro, portal centrado no debate e na divulgação das questões concernentes à poesia e à tradução, Júlia descreve, a partir de uma metáfora alicerçada na animalidade, o processo de operacionalização poética: “(...) entendo que o fio da linguagem que mora no poema é como um cavalo que cavalgasse a fronteira limite, entre ocupação material \& o vazio e que, no fundo, é a linha limítrofe entre a vida e a morte também" (HANSEN, 2018, p. 02)1. Penso que a poeta elabora ludicamente as relações entre fronteiras, como se os contornos fossem matéria plástica plena de possibilidades, talvez apenas esperando o contato com a caneta para que se remodelem em um jogo infindável de transmutação. O seguinte trecho do poema do qual furtei o título da entrevista me parece um plano concreto dessa poética multifatorial:

\footnotetext{
Noite dessas pari uma acaso danado, depois percebi que era só a rua me deixando passar Já sou poeta e não sei já (HANSEN, 2013, p. 42)
}

A partir de um positivo pré-conceito concernente às muitas facetas de Júlia de Carvalho Hansen, poeta, astróloga, editora e crítica literária, tomarei como norte desta entrevista formular com a entrevistada uma conversa sobre o entre-lugar. Me interessa, particularmente, as combinações entre poética e edição, as questões astrais em meio à criação artística e o lugar da crítica literária junto a esses movimentos.

\footnotetext{
* Pontifícia Universidade Católica de Minas Gerais (PUC Minas). Mestrando em Literatura de Língua Portuguesa pela PUCMinas. Bolsista CNPQ.

1 HANSEN, Júlia. Entrevista com Júlia de Carvalho Hansen. Disponível em: <https://escamandro.wordpress. com/2017/03/06/entrevista-com-julia-de-carvalho-hansen/> Acesso: 10 jan 2018. Entrevista concedida a Sergio Maciel. 2 HANSEN, Júlia de Carvalho. Alforria blues ou Poemas do Destino do Mar. Belo Horizonte: Chão de Feira, 2013.
} 


\section{Conversa}

Otávio Moraes: Em sua dissertação Convívio e Dispersão: da Tradição Poética em Ensaios de Antônio Ramos Rosa e Haroldo de Campos você comenta, especificamente na apresentação, que, a princípio, sua busca desenvolveu-se no sentido de tematizar as correlações entre o conceito de invenção e a temporalidade contemporânea, mas que o desenvolver da pesquisa a levou para outros caminhos conceituais e que essa primeira questão talvez dissesse mais respeito a você do que aos ensaístas objeto de seu estudo. Continua atual seu interesse na relação entre a inventividade e a poesia contemporânea? Sob uma ótica dupla, na posição de quem cria e de quem lê a poesia produzida em nosso tempo, o que configura uma poética inventiva? E como você conceituaria o contemporâneo?

Júlia de Carvalho Hansen: Quando comecei a estudar no meu mestrado, eu queria aprender com alguns poetas modernos o que eles consideravam mais fundamental como gesto para se escrever alguma coisa relevante e que dure mais que um espirro. Era um problema narcísico: eu queria fazer alguma coisa durável no mundo. Ao mesmo tempo, a modernidade literária tem um problema de legitimação fundamental: como não há modelo prévio, o que é poesia? E como definir o que, na imensa massa amorfa das produções poéticas, é o relevante? Aí se buscam palavras pra legitimar: "inovação", "originalidade", "novidade", uma série de termos que funcionam como elos, como ignições para determinar a qualidade de alguma coisa. São critérios como quaisquer outros, mas são também palavras genéricas: o que pode ser uma inovação pra mim pode não ser pra você, e vice-versa. Justamente por serem pouco específicos para além das valorações de uma pessoa ou de um determinado grupo de pessoas, são critérios que podem ser aplicados a qualquer coisa, costumam bem servir conforme o desejo e o ambiente.

"Invenção" é um pouco parecido com os termos que mencionei anteriormente, mas acho que é menos genérico, porque tem um quê de engrenagem: a invenção é capaz de funcionar como um grilofalante, um pequeno mecanismo que se movimenta por si. Quando você encosta os olhos num poema e ele gruda em você; quando, ao ler, sente as palavras se movimentarem por si próprias numa articulação caminhante como, digamos, as patas de um grilo se articulam ou as asas de uma cigarra cantando vibram códigos de comunicação, acesso, direção: eis algo inventado, vivo. Entendo que a invenção poética, quando acontece, abre conteúdos, ações, emoções, faz vibrar, liga as coisas em que se liga. Se não faz isso, não é um poema. O que faz uma invenção acontecer? Ousadia, treino, conhecimento, talento, dom, trabalho, consciência, recusa, crivo, transe... são tantos caminhos possíveis que nem dá pra saber se há algum certo.

Quandocomeceiafazerminhapesquisademestrado em 2011 eu não estava exatamente interessada na produção poética do "contemporâneo", não, mas em ser contemporânea a mim mesma, ao meu próprio tempo. Pra entender como me posicionar no mundo achava que teria que estudar o "contemporâneo", mas o que ficou rapidamente claro pra mim lendo ensaios de vários poetas do século XX é que precisaria estudar a noção de "tradição", e foi o que eu fiz. Além dos autores mencionados no título do trabalho, pesquisei conjuntos de ensaios de T.S. Eliot, Ezra Pound e Octavio Paz, três senhores mortos para quem a "tradição" e o que fazer com ela é a "questão" da poesia moderna. Ainda concordo com a prevalência que esses autores dão para a "tradição" e hoje sei com alguma tranquilidade que eu mesma sou uma pessoa cheia de questões com os ancestrais.

Todo meu trabalho com minha dissertação coincidiu temporalmente com toda a escrita do meu segundo livro "alforria blues ou Poemas do Destino do Mar" (Chão da Feira, 2013), onde eu buscava uma língua original e/ou inventiva. Hoje, ou desde o "Seiva veneno ou fruto" (Chão da Feira, 2016), eu simplesmente escrevo. Também acho que um poeta precisa de tanta audácia e esquecimento como de um bom pé fincado no mundo dos mortos. Nesse sentido, concordo com o que diz Marina Tzvetaieva de que podemos 
ser contemporâneos dos mortos que escolhemos como nossos contemporâneos tanto quanto dos vivos.

Embora ainda utilize "invenção" como valoração pro que leio e escrevo, no fundo acho que o seu uso atual é bastante carregado duma espécie de egocentrismo centrado na "originalidade" ou na "novidade", categorias que quando eram só românticas já eram problemáticas, mas que com as práticas comerciais atreladas à circulação dos livros e as estrelas de avaliação dos jornais são mesmo só tags que duram uma ou duas estações. Tags, como sabemos, são aplicáveis a qualquer coisa. No mais, manter "invenção" como paradigma talvez tenha sido um meio com que os modernos viraram as questões retóricas do mundo antigo do avesso, mas mantendo uma espécie de plano/projeto/roteiro de ação. No limite, como qualquer projeção linear das coisas precisa ser observada como a ilusão que é, acho que ter a invenção como alvo é uma bobagem. Ao mesmo tempo, quando em um texto alguma invenção acontece, ela brilha por si. Ou seja: depois de tantas linhas ditas: eu mesma ainda não sei muito bem o que fazer com a "invenção" ela ainda me importa enquanto questão, embora a cada dia com menos centralidade, não dou mais a ela tanto valor.

Quanto à produção poética dos contemporâneos vivos, embora tenha interesse em ler o que é produzido e publicado, tenho muita dificuldade em acompanhar o excesso de publicação. Como se sabe, nos últimos 15 anos tem acontecido uma facilitação dos acessos às técnicas editoriais, o que é uma libertação pra ser comemorada inclusive isto permitiu e permite que todos os meus livros já publicados tenham sido impressos. Gosto da pluralidade, da dissonância, mas também há muito lugar comum e são tantas as vozes falando ao mesmo tempo que desconfio que quase ninguém esteja se ouvindo de fato.

É muito difícil e exigente escutar-se de fato, e tão exigente e difícil quanto é escutar o outro. Sem escuta não há escrita. E além de escutar: como ao mesmo tempo ter corpo, mente, espírito, coração, saúde e integridade pra lidar com os tempos difíceis em que estamos no mundo, num país em que todas as instituições desmoronaram e seguem como zumbis e vampiros, como lidar com a vida num tempo governado por ilegítimos, pela ilegitimidade? Como conviver com isso, lutar contra isso, sem nunca alimentar nenhum dos fascismos, dos moralismos que só crescem? Como lidar? Como escrever? Como andar em meio ao horror sem alimentá-lo? Não faço a menor ideia. Mas vou tateando. Também porque concordo com o que diz o Agamben de que o contemporâneo é o escuro, a escuridão, aquilo que a gente não consegue ver. Quem tem olhos para ver e ouvir e estar no escuro?

OM: O poeta e crítico Haroldo de Campos vislumbra outras maneiras de exercício da crítica literária além de um plano tradicional, usualmente mais acadêmico, de tomada deste objeto. A criação poética é apresentada como uma plataforma que, na Modernidade, integrase ao exercício crítico ao tomar como objeto seu próprio processo constitutivo. Sob esse enfoque, como o exercício de reflexão sobre a literatura, via produção literária, se constituem no seu exercício poético?

JCH: Acho admirável a ligação de fazeres que o Haroldo de Campos realizou entre poesia e crítica e concordo com ele, claro, quando faz a aproximação dos gestos críticos e poéticos. Pra mim essas duas tarefas estão sempre ligadas, mas também acho um pouco rebuscado demais. No fundo, acho que o Haroldo dizia com isso o mesmo que todos os poetas de uns 300 anos pra cá quando procuram falar sobre escrever: estão/ estamos a procurar uma narrativa, uma mitologia, um discurso que legitime a própria experiência poética. Também quero dizer com isso que conheço e reconheço muitos poetas excelentes para quem a crítica é só um pé no saco. Por mais que possamos argumentar que isso também é um tipo de recorte crítico do pensamento de tais poetas, essa visão é legítima e produz, muitas vezes, resultados mais interessantes do que os muito cerebrais. Mas também existem, claro, poemas que são exercícios críticos e textos críticos que são experimentações poéticas. 
Ao mesmo tempo, entendo que a crítica é muito fundamental e que ela está muito mais em queda, muito mais em risco do que a poesia hoje em dia. Adoro a palavra "crivo", é das minhas palavras fundamentais. Considero importante defender a crítica como paradigma por si próprio. Por exemplo, há resenhas de livros saindo em tantos veículos, mas quantas delas passam de uma mera apresentação do conteúdo do livro? O que escapa dos coleguismos de marcar um ou outro autor numa postagem de Facebook?

Vejo estudantes de Letras querendo se libertar da crítica porque ela seria mais careta, restritiva ou banal - o que é uma imensa bobagem. Cresci ouvindo intelectuais debatendo e ainda hoje entendo que poucas coisas podem ser mais estimulantes do que conversas entre pessoas afiadas e com espaço pra afiarem-se umas às outras. Quer dizer: na minha visão, que é também a minha criação, o intelectual vive há milêniosluz do acadêmico. E embora gostasse dumas estruturas gregárias, o Haroldo nunca foi um acadêmico. Pelo contrário, foi dos pensadores e poetas e tradutores mais livres e pertinentes que já existiu neste território brasileiro. Era um intelectual poeta, um poeta intelectual. Erudito, culto, experimental, bem como seus textos definiam e defendiam a poesia e a crítica.

No limite, o que é um acadêmico? Algo como: aquele que baliza o pensamento na mediocridade normativa das falas em comum que servem a um cenário de legitimação creditado por si próprio e que responde automaticamente aos valores dos seus convívios. O pessoal da academia quando defende o poético no crítico muitas vezes simula os textos dos seus objetos de estudo e não consegue muito mais do que uma atmosfera de poético com isso. Acho também que muitas vezes em que os críticos procuram legitimar o poético nas suas escritas estão mais é procurando um motivo ou uma teoria que lhes ampare o medo do desbunde. O desbunde real da falta de sentido: quem quer experimentar? É uma perdição danada e, ao meu ver, só é poeta quem também enfrenta esse lugar em que a língua delira.

Por fim, também acho que há uma confusão que é mais de uma ordem dos códigos sociais do medo dentro das universidades: uma confusão de que o texto de cunho intelectual crítico seria mais "entediante" ou "convencional" e, em contraponto, a criação poética seria mais "original" ou "livre", o que é uma imensa bobagem. Conheço ensaios de uma formalidade acadêmica e não-poética que são absolutamente fascinantes, e poemas que se consideram criativos e que só dão bocejos. Tudo depende tanto... A linguagem burocrática pode aparecer a qualquer instante, Kafka falou tanto disso... A sintaxe em si já é uma espécie de burocracia, talvez esse seja o problema. E acho que tanto a crítica como a poesia interessam quando burlam o burocrático.

OM: Aproveitando a deixa haroldiana, você traduz, já traduziu ou tem desejo de embrenharse pela atividade tradutorial no plano poético, ou, mesmo, já auxiliou na tradução de alguma de suas escritas? Em caso de resposta afirmativa, você experimentou paralelos com seu processo de criação poética?

JCH: Não, não tenho nenhuma fascinação com as traduções. De vez em quando traduzo letras de música para que eu mesma possa entender como ligam palavras aos tons emocionais das partes musicais e imagino como isso se daria se não fosse o "suporte" musical. Mas são brincadeiras rápidas, quase sempre exercícios só de pensamento, distrações do momento, coisas que faço andando na rua e de fones de ouvido e que, como não registro, até esqueço que fiz. Algumas vezes traduzo a partir da tradução que leio fazendo uma versão que eu gostaria mais, mas também só dura um instante. Uma prática textual de tradução não tenho, não, talvez com o passar dos anos eu passe a traduzir alguma coisa, mas hoje em dia sinto que já tenho problemas demais para lidar com a sintaxe do português.

OM: No que se refere à atividade de editora, na página de vocês (Chão da Feira) está posta a frase "Editamos como quem planta. Podar para crescer". É interessante pensar nessa metáfora em paralelo à sua escrita. Em Alforria blues ou Poemas do Destino do Mar você utiliza a imagem 
do cavalo como elemento de representação do poético; outros elementos naturais externos ao humano são abundantes na obra; em seu mais recente livro Seiva Veneno ou Fruto, a questão vegetal é acentuada. Eu vejo, em um primeiro plano, semelhanças entre a apresentação editorial e a sua escrita como poeta. Você vislumbra como um processo uno o da produção literária, como se editar e escrever literatura não tivessem fronteiras? Para o sim ou para o não, em que ser poeta implica em seu exercício editorial?

JCH: Acredito que enquanto coletivo na Chão da Feira temos uma visão ecológica das coisas, uma noção de que o que importa é que o que é vital cresça e, simultaneamente, que sem crivo e critério não se faz uma boa editora. Isto coincide com a minha poesia, sim.

Mas acho que entre escrever e editar existem muitas fronteiras. Pra mim, escrever um poema é muitas vezes um transe, um ir pro outro lado sem saber com o que se vai voltar: pra se escrever um poema é preciso ser/estar meio cega; já a edição é sobretudo uma aposta da lucidez: a edição precisa de olhos muito abertos. Se bem feitas, ambas as tarefas são tipos diferentes de generosidade e dádiva.

Além disso, o que mais gosto em editar é chegar até a materialidade final dos textos impressos no papel. Adoro pegar na mão um livro bem feito e é uma alegria constante e também uma honra fazer parte da Chão da Feira. Mas não sei se eu seria editora em todo e qualquer contexto ou se sou mais uma editora de circunstância, uma pessoa privilegiada por trabalhar tantas vezes com a Carolina Fenati e a Luísa Rabello. Não sei dizer se eu, necessariamente, seria editora num outro contexto que não esse.

OM: A maneira como você elabora uma certa intimidade com o mundo vegetal e animal me dá a impressão de uma politicidade intrínseca, não em uma perspectiva panfletária necessariamente vinculada a um grupo político $\mathrm{x}$ ou $\mathrm{y}$, mas sob uma ótica mais profunda, como se poetar fosse reivindicar, compor e recompor o mundo que te rodeia. Você entende sua poesia como uma escrita empenhada politicamente? Qual o papel político dos poetas contemporâneos?

JCH: Sem dúvida considero os escritos que publico políticos, a cada dia mais tento abordar as questões fundamentais pra mim e (talvez também) pra espécie humana sobreviver a si mesma. Acho que há uma ética na poética, por exemplo, quando escolho de que modo ou quais temas abordar e de quais coisas não tratar. Quando falo de animais, planetas, vegetais ou mesmo mais recentemente do amor (o livro que estou escrevendo agora é todo de poemas de amor) são decisões bem intuitivas, mas são opções pelo que me parece fundamental. Quando estou no meio da redação desses poemas e livros sinto mesmo uma espécie de confirmação, entendo que estou optando politicamente por tratar o que considero urgente, muitas vezes numa cegueira induzida e indireta, quando escolho não tratar de temas que são mais explícitos politicamente. Por exemplo, tento todos os dias não sucumbir ao mal-estar, ao pessimismo e à violência das interpretações que estão em voga. Consciente de que é tudo um grande em-comum, encontro tantas vezes a dissonância. Qual o negativo do negativo?

No mais, acho que acredito numa certa ecologia dos princípios, ou faço isso pra gozar bem da minha saúde frágil, e isto se desdobra, por exemplo, nas minhas aproximações dos reinos vegetais e dos animais, do "other-than-human" que muitos antropólogos têm discutido e que são mesmo (eu acho) o que é vital. Ao mesmo tempo, tanto as plantas quanto os animais sempre foram meus interesses desde muito criança e às vezes me pergunto se não seria só um jogo o que estou a fazer, ou algo com um sentido mais implacável, se não estou sempre a afirmar que a diferença desta espécie humana é o que me interessa, afinal a palavra é do meu reino, o código desta espécie em que somos/estamos, e nada me interessa mais do que ter acesso à palavra e fazer isto com consideração.

No mais, acho que viver é um problema político: quero dizer com isso que acho que o papel político não é dos poetas contemporâneos ou dos leitores ou dos jardineiros ou dos médicos, o papel ético- 
estético-político é um problema generalizado que permeia a vida toda, desde o modo como alguém compra pão na padaria e se relaciona com cada uma das pessoas do seu dia a dia; ou também se rega ou não as plantas do jardim: todos os gestos são políticos.

Agora, como cada poeta vai lidar ou não com isso eu acho que é uma resposta singular, única. Se vejo uma tarefa para a poesia contemporânea é a de não legislar ou normatizar nada (nem a poesia) nem ninguém. 